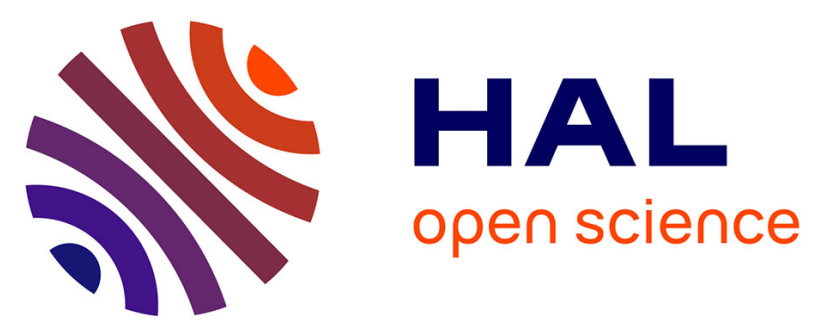

\title{
Do species population parameters and landscape characteristics affect the relationship between local population abundance and surrounding habitat amount?
}

Benoit Ricci, Pierre Franck, Muriel Valantin-Morison, David Bohan, Claire Lavigne

\section{To cite this version:}

Benoit Ricci, Pierre Franck, Muriel Valantin-Morison, David Bohan, Claire Lavigne. Do species population parameters and landscape characteristics affect the relationship between local population abundance and surrounding habitat amount?. Ecological Complexity, 2013, 15, pp.62-70. 10.1016/j.ecocom.2013.02.008 . hal-01003336

\section{HAL Id: hal-01003336 https://hal.science/hal-01003336}

Submitted on 29 May 2020

HAL is a multi-disciplinary open access archive for the deposit and dissemination of scientific research documents, whether they are published or not. The documents may come from teaching and research institutions in France or abroad, or from public or private research centers.
L'archive ouverte pluridisciplinaire HAL, est destinée au dépôt et à la diffusion de documents scientifiques de niveau recherche, publiés ou non, émanant des établissements d'enseignement et de recherche français ou étrangers, des laboratoires publics ou privés. 


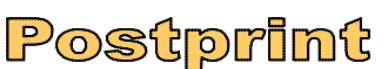

Version définitive du manuscrit publiée dans / Final version of the manuscript published in :

Ecological Complexity (2013), Vol. 15, p. 62-70, DOI: 10.1016/j.ecocom.2013.02.008

Journal homepage: www.elsevier.com/locate/ecocom

\section{Abstract}

In Landscape Ecology, correlational approaches are typically used to analyse links

3 between local population abundance, and the surrounding habitat amount to estimate

4 biologically-relevant landscape size (extent) for managing endangered or pest populations.

5 The direction, strength, and spatial extent of the correlations are then sometimes interpreted in terms of species population parameters. Here we simulated the population dynamics of generalized species across spatially explicit landscapes that included two distinct habitat types. We investigated how characteristics of a landscape (structure), including the variation in habitat quality and spatial aggregation of the habitat, and the precise population-dynamic properties of the simulated species (dispersal and growth rates) affect the correlation between population abundance and amount of surrounding, favourable habitat in the landscape. To evaluate the spatial extent of any correlation, proportions of favourable habitats were calculated in several circular buffers of increasing radii centred on sample patches of

\section{4 favourable, where population abundance was recorded.}

We found that the value of the correlation coefficients depended both on population dynamics parameters and landscape characteristics. Correlation coefficients increased with the variation in habitat quality and with aggregation of favourable habitat in the landscape.

The distance to highest correlation was sensitive to the interaction between landscape characteristics and the population dynamic properties of the simulated species; in particular between the variation in landscape quality and the dispersal rate. Our results corroborate the view that correlational analyses do provide information on the local population dynamics of a species in a given habitat type and on its dispersal rate parameters. However, even in 


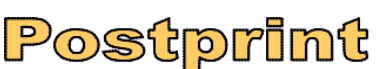

Version définitive du manuscrit publiée dans / Final version of the manuscript published in :

Ecological Complexity (2013), Vol. 15, p. 62-70, DOI: 10.1016/j.ecocom.2013.02.008

Journal homepage: www.elsevier.com/locate/ecocom

\section{1. Introduction}

Understanding species abundance, as function of the habitat characteristics of a

3 landscape and the population-dynamic properties of the species, is important for guiding

4 landscape management policy for biodiversity conservation (Jeanneret et al., 2003; Aldridge and Boyce, 2007; Ockinger and Smith, 2007), and the control of invasive species (SebertCuvillier et al., 2008; McKee et al., 2009) and of crop pests (Bianchi et al., 2006). Correlations between local population abundance in focal sampling patches and the surrounding habitat amount in buffers of increasing size have been used to identify both the important landscape features that compose the habitat of a species and their scale of effect (Brennan et al., 2002). This 'focal sampling patches approach' has been widely used by Conservation Ecologists for a number of years (Vos and Chardon, 1998) and is now used for pests in agro-ecosystems with a view to landscape-level management (e.g. Schmidt et al., 2005; Decante and Van Helden, 2006; Zaller et al., 2008; Ricci et al., 2009; Rusch et al., 2010). Observed correlations between population abundance and the amount of surrounding habitat have been interpreted in an intuitive fashion; a positive correlation between population abundance and the area of a landscape feature indicates that this feature is a "good quality" habitat for the species, and vice versa. Numerous empirical studies have thus interpreted the direction and the value of landscape correlations in terms of quality of the habitat (Roschewitz et al., 2005; Bianchi et al., 2006; Moser et al., 2009; Ricci et al., 2009; Veres et al., 2012).

The spatial extent of the correlations has also been interpreted in terms of underlying ecological processes (Wiegand et al., 1999; Jepsen et al., 2005; Turner, 2005; Schroder and metric of patch connectivity that explains the frequency of colonization events (Moilanen and Nieminen, 2002; Bender et al., 2003). Some authors have investigated the spatial extent at which correlations arise, using empirical approaches, in order to shed light on the scale of 


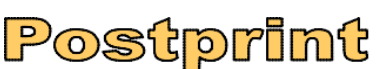

Version définitive du manuscrit publiée dans / Final version of the manuscript published in :

Ecological Complexity (2013), Vol. 15, p. 62-70, DOI: 10.1016/j.ecocom.2013.02.008

Journal homepage: www.elsevier.com/locate/ecocom

1 effect of particular landscape features of species habitat (Thies et al., 2003; Carrière et al.,

2 2006). The maximal extent of significant correlation (e.g. Carrière et al., 2006), range of

3 distances that provide significant correlations (e.g. Roschewitz et al., 2005; Thies et al., 2005)

4 and the distance that has the strongest correlation (e.g. Thies et al., 2003) are statistics that

5 have all been used to infer the spatial scale of landscape characteristics. More recently, it has

6 become clear that landscape correlation effects depend both on population-demographic

7 processes and landscape structure. Jackson and Fahrig (2012) demonstrated through simulated

8 population-dynamic models that the scale of effect (measured as the distance that has the

9 strongest correlation) depends on species population parameters, most notably species-

10 specific dispersal. The spatial distribution of a species over a landscape depends, in turn, not

11 only on its population dynamics but also on the landscape composition and structure

12 (Tischendorf, 2001, Campagne et al., 2009).

The impact of landscape structuring (habitat amount and spatial aggregation) on the

14 outcome of focal sampling patches approaches has been found to depend on efficiency of dispersal over the landscapes. The efficient movement of individuals among habitats, at the landscape scale, depends both on the dispersal abilities of a species and on the subsequent realised probability of success of immigration; a probability that is directly related to the aggregation of good quality habitat (Ricketts, 2001; Baguette and Van Dyck, 2007; Reeve et al., 2008). These population-dynamic effects of aggregation of the habitat on the correlation between local abundance and surrounding habitat amount remain to be deeply explored (but 21 see Wiegang et al. 1999).

The relative proportion of high $v s$. low quality habitat, and the intensity of the contrast between these habitat types are also important factors affecting landscape correlations. By definition, high quality habitat provides enough resources to allow higher population growth rates and/or carrying capacities than low quality habitat (Moilanen and Hanski, 1998). Low 


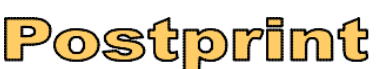

Version définitive du manuscrit publiée dans / Final version of the manuscript published in :

Ecological Complexity (2013), Vol. 15, p. 62-70, DOI: 10.1016/j.ecocom.2013.02.008

Journal homepage: www.elsevier.com/locate/ecocom

1 quality habitats may act as population dynamic sinks (Pulliam, 1988) and/or slow down

2 population expansions from high quality habitats (Thomas and Kunin, 1999). Models of

3 heterogeneous landscape usually simulate extreme cases, with only patches of favourable

4 habitat set in an unfavourable matrix (Wiegand et al 1999; Jackson and Fahrig, 2012). In real

5 landscapes, however, species are often able to grow and survive across a variety of different

6 habitat types with a range of levels of success. The effects of the quality contrast between

7 habitats and the relative proportions of each habitat in landscape on focal sampling patches

8 approach correlations have yet to be documented, although we would expect that

9 heterogeneity in habitat qualities should markedly impact the magnitude of landscape

10 correlation.

This paper explores how species population parameters (dispersal, growth rate) and

12 landscape properties (amount and spatial aggregation of favourable habitat) mediate the

13 correlations between local abundance in focal sampling patches and surrounding habitat

14 amount. Using a spatial population dynamic model, we simulate the spatial distribution of

15 population abundance in landscape composed of low and high quality habitat at differing

16 levels of spatial aggregation. We sample the population abundance in 25 focal patches in each

17 landscape and calculate the correlation between local population abundance in these focal

18 patches and the amount of high quality habitat across buffers of increasing size. We analyse

19 how this correlation is influenced by: i) variation in habitat quality, both across differing

20 relative amounts of high and low quality habitat and for a variety of quality contrast between

21 habitat types; and, ii) an interaction of landscape structure (level of spatial aggregation of each

22 habitat) and species dispersal parameters (dispersal rate and dispersal function). 


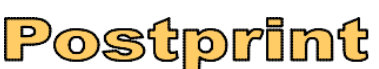

Version définitive du manuscrit publiée dans / Final version of the manuscript published in :

Ecological Complexity (2013), Vol. 15, p. 62-70, DOI: 10.1016/j.ecocom.2013.02.008

Journal homepage: www.elsevier.com/locate/ecocom

\section{2. Material and Methods}

2

4

\subsection{General approach}

Our scheme of spatially-explicit simulation modelling took place in two clear steps (Fig. 1 and Table 1). In the first set, we investigated the effect of variation in habitat quality on the overall pattern of correlation by varying both the proportion of low $v s$. high quality habitat and the difference in population growth rate between high and low quality habitats. In the second set, we addressed the impact of landscape spatial aggregation and dispersal on the pattern of correlation by varying the amount of aggregation of high quality habitat and the population dispersal parameters (dispersal rate and dispersal type). This second step in the simulation modelling fixed as constant the habitat quality at the values which provided maximal correlations in the first step of the simulation scheme.

\subsection{Landscape modelling}

\subsubsection{Landscape composition}

The simulations took place across landscapes of 3600 cells in a regular $60 \times 60$ grid. The square cells had sides of one arbitrary unit, $D$, were either of high quality habitat $\mathrm{H}$ (in proportion $P_{H}$, in which any population would have a high growth rate $\left(r_{H}=0.07\right)$, or of low quality habitat L (in proportion 1- $P_{H}$ ), in which a population would had a low growth rate $\left(r_{L}\right)$. Contrasted effects between high and low quality cells, were simulated by varying the growth rate differences between $\mathrm{H}$ - and L-habitats $\left(\delta=r_{H}-r_{L}\right)$. In the first set of simulations, each combination of proportions of H-cells $\left(P_{H}=0.10,0.25,0.50,0.75\right.$ or 0.90$)$ and habitat contrasts $(\delta=0.02,0.04,0.06)$ was considered in order to compare landscapes with differing qualities (Fig. 1 and Table 2). In the second set of simulations, $P_{H}$ and $\delta$ were fixed as constants, respectively at 0.5 and 0.06 , as this combination of values was found to maximize the correlation coefficients in step 1 (see results below). 
Version définitive du manuscrit publiée dans / Final version of the manuscript published in :

Ecological Complexity (2013), Vol. 15, p. 62-70, DOI: 10.1016/j.ecocom.2013.02.008

Journal homepage: www.elsevier.com/locate/ecocom

2 2.2.2. Spatial aggregation of habitat quality within the landscape

For the first set of simulations, we generated random landscapes $\left(S_{0}\right)$ in which L-cells

4 and H-cells were distributed in a spatially random pattern on the grid for each proportion of

5 high quality cells (10 replicates for each $P_{H}$ value). For the second set of simulations, we

6 generated landscapes with spatial aggregation of habitat quality, for the given value of $P_{H}=$

$7 \quad 0.5$, using the method detailed by Wiegand et al. (1999). At 250 spatially random locations

$8\left(x_{0}\right)$, we calculated two-dimensional Gaussian functions of form:

$9 \quad G(x)=\frac{1}{\sigma \sqrt{2 \pi}} \exp \left(-\frac{\left(x-x_{0}\right)^{2}}{2 \sigma^{2}}\right)$

10 These functions were superimposed, forming a surface of different elevations that we split by

11 a horizontal plane thus classifying areas of the landscape above or below the plane into either

$12 \mathrm{H}$-cells or L-cells. The height of the plane was chosen so that the proportion of cells $\mathrm{H}$ was

13 equal to 0.5 . Two values of $\sigma$ were used to design landscapes with aggregation of habitat

14 quality with either relatively small ( $\sigma=1$, designated landscape-type $S_{l}$ ) or relatively large

$15\left(\sigma=3\right.$, designated landscape-type $\left.S_{2}\right)$ clusters of high and low quality cells. Ten replicates of

16 each $S_{1}$ and $S_{2}$ landscapes were generated for the second set of simulations and we reused the

1710 replicates of $S_{0}$ from the first set. Example maps of the generated landscapes are provided

18 in Fig 2 (see also Fig. A1 and Fig. A2 in the Supplementary Material).

19

\subsection{Population dynamics}

21 2.3.1. Population growth

22 Each cell hosted a population initially composed of two individuals that grew

23 logistically. The carrying capacity of each cell was set to $K=100$ and the growth rate was $r_{H}$ or

$24 r_{L}$ depending on whether the population was in a H- or L-cell, respectively. The growth rate in 


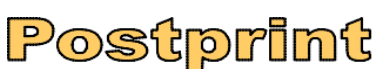

Version définitive du manuscrit publiée dans / Final version of the manuscript published in :

Ecological Complexity (2013), Vol. 15, p. 62-70, DOI: 10.1016/j.ecocom.2013.02.008

Journal homepage: www.elsevier.com/locate/ecocom

$1 \quad \mathrm{H}$-cells was kept constant $\left(r_{H}=0.07\right)$, defining a reference situation. In the first set of

2 simulations, growth rates in L-cells were either $r_{L}=0.01$ or 0.03 or 0.05 in order to vary cell

3 quality contrasts $\left(\delta=r_{H}-r_{L}=0.06,0.04,0.02\right)$ between $\mathrm{H}$ - and L-habitats (Fig. 1$)$. In the

4 second set of simulations, $\delta$ was kept constant $\left(\delta=0.06, r_{L}=0.01\right)$.

Preliminary simulations showed that the maximal difference between the mean

6 population abundance in H- and L-cells, in random landscapes, occurred after 75 time steps

7 (See Fig. A3 in the Supplementary Material). 75 time steps was therefore chosen as the

8 terminal duration of each simulation.

9

2.3.2. Dispersal

At each time step, a proportion $m$ (dispersal rate) of the population in each cell dispersed

to other cells according to one of four, predefined dispersal models:

- Stepping stone (Step): individuals dispersing from a given cell had an equal probability of moving to each of the four nearest cells situated at a distance of 1 . This

- Twelve nearest neighbours (12nn): individuals dispersing from a given cell had an model corresponds to a classical two dimensional stepping stone. equal probability of moving to each of the twelve nearest cells; corresponding to a maximal distance of 2 from the source cell.

which most individuals moved to nearby cells, while a few individuals dispersed to cells further away. A bivariate Student's dispersal distribution (2Dt) was used to determine the probability of a individual dispersing from one cell arriving in any other, as given by: $P=\frac{b-1}{\pi a^{2}}\left(1+\frac{d^{2}}{a^{2}}\right)^{-b}$ 


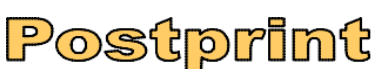

Version définitive du manuscrit publiée dans / Final version of the manuscript published in :

Ecological Complexity (2013), Vol. 15, p. 62-70, DOI: 10.1016/j.ecocom.2013.02.008

Journal homepage: www.elsevier.com/locate/ecocom

where $d$ is the distance between the two cells, $a$ is a scale parameter and $b$ is a parameter that determines the weight of the distribution tail. The parameters $a$ and $b$ were set at $a=3$ and $b=3.5$, so that the mean distance of dispersal was approximately 2 and about $25 \%$ of dispersal events were above this mean distance. The probability was then normalized to ensure that all dispersing individuals from any source cell found a target cell.

- Random: all individuals dispersing from a cell moved randomly with equal probability to other cells (Wright, 1931). This dispersal model was used as a control, with the expectations that no significant correlations should be observed.

The probability distributions associated to these four models have different average dispersal distances $(\bar{d})$. The average dispersal distance progressively increases from the Step model $(\bar{d}=1)$ to the Random dispersal model ( $\bar{d}=31.28$ in a $60 \times 60$ grid), with the $12 n n$ $(\bar{d}=1.47)$ and the $2 D t(\bar{d}=2.12)$ models displaying intermediate average distances of dispersal (see Fig. A4 in the Supplementary Material for the shapes of the dispersal functions). Only the $12 n n$ dispersal model was used for the first set of simulations. The four dispersal models were contrasted in the second set of simulations (Fig. 1).

\subsection{Details of the two simulation sets}

\subsubsection{Set 1}

In the first set of simulations (Fig. 1), the effect of the variation in landscape-level habitat quality, $Q$, on correlation patterns was assessed on random landscapes, $S_{0}$, using constant dispersal parameters (dispersal model $12 n n$ and $m=0.075$ ). $Q$ was calculated as the coefficient of variation of growth rates over all cells from the grid:

$$
Q=\frac{\sqrt{P_{H}\left(r_{H}-\bar{r}\right)^{2}+\left(1-P_{H}\right)\left(r_{L}-\bar{r}\right)^{2}}}{\bar{r}},
$$




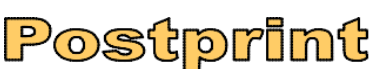

Version définitive du manuscrit publiée dans / Final version of the manuscript published in :

Ecological Complexity (2013), Vol. 15, p. 62-70, DOI: 10.1016/j.ecocom.2013.02.008

Journal homepage: www.elsevier.com/locate/ecocom

1 where $P_{H}$ is the proportion of high quality habitat, $r_{H}$ the growth rate in high quality habitat, $r_{L}$

2 the growth rate in low quality habitat and $\bar{r}$ the mean growth rate over the landscape

3 calculated as:

$4 \quad \bar{r}=P_{H} r_{H}+\left(1-P_{H}\right) r_{L}$

$5 Q$ varied across the five values of $P_{H}$, each with 10 replicates, and the three values of quality

6 contrast between the habitats $\left(\delta=r_{H}-r_{L}=0.06,0.04,0.02\right)$, yielding a total of 150

7 simulations (Table 2).

8

9

\subsubsection{Set 2}

In a second set of simulations (Fig. 1), we assessed the effect of landscape spatial

11 aggregation and dispersal on the patterns of correlation. For this set of simulations, we fixed

as constant landscape-level variation in habitat quality at $Q=0.75$ (i.e. $P_{H}=0.5$ and $\delta=0.06$ ),

which the preceding set of simulations demonstrated to provide maximal correlation

coefficients. Simulations were run over 10 replicates of each of the three levels of aggregation

of habitat quality $\left(S_{0}, S_{1}\right.$ and $\left.S_{2}\right)$ for each combination of the four dispersal models (Step,

$12 n n, 2 D t$ and Random $)$ and three different dispersal rates $(m=0.05,0.075$ and 0.100$)$. This

gave a total of 360 simulations (30 landscapes x 4 dispersal models x 3 dispersal rates).

\subsection{Correlations between local population abundances and amount of}

For each suite of demographic and landscape parameters, the simulation results were

analysed after 75 time steps using a focal sampling patches approach. We randomly picked 25

H-cells, as focal patches, such that each of these selected cells was situated at a: i) distance 


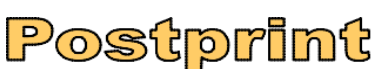

Version définitive du manuscrit publiée dans / Final version of the manuscript published in :

Ecological Complexity (2013), Vol. 15, p. 62-70, DOI: 10.1016/j.ecocom.2013.02.008

Journal homepage: www.elsevier.com/locate/ecocom

1 maps in Fig. 2). We then calculated and evaluated the significance of Spearman correlations

2 between population abundances in each of the 25 focal cells and the proportions of $\mathrm{H}$-cells

3 surrounding the focal cells. In order to describe and compare correlation patterns among

4 simulations, correlation coefficients were calculated in four buffer zones (D1,D2,D3 and D4)

5 of different radii $d$ surrounding each focal cells ( $d=1,2,3$ and 4, respectively). Three

6 commonly used indicators were recorded to describe correlation patterns (Table 1): the value

$7 R m$ of the highest correlation coefficient, and two measures of the scale of effect namely the

8 distance $D m$ at which $R m$ was achieved (e.g. Jackson and Fahrig, 2012), and the greatest

9 distance $D s$ at which a significant correlation occurred (e.g. Carrière et al., 2006). Ds was

10 assumed to be 0 when no correlation was significant.

\section{Results}

All significant correlations ( $85 \%$ of correlations) were positive in simulations with the Step, $12 n n$ and $2 D t$ dispersal models, indicating that local population abundances in sampling cells were higher in cells surrounded by a large proportion of $\mathrm{H}$-cell. Correlations averaged $0.65 \pm$ sd 0.22 for the three dispersal models (Table 3). As expected, in the Random dispersal model used as reference, $6 \%$ of correlations were significant, which is little more than that expected by chance.

\subsection{Effects of the variation in habitat quality on the correlation patterns}

The shape of the correlation coefficient curves with increasing $Q$ was similar for all 


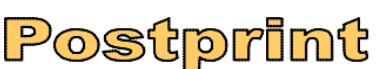

Version définitive du manuscrit publiée dans / Final version of the manuscript published in :

Ecological Complexity (2013), Vol. 15, p. 62-70, DOI: 10.1016/j.ecocom.2013.02.008

Journal homepage: www.elsevier.com/locate/ecocom

1 the smallest buffer, $D 1$, and larger for the buffer, $D 2$ (Fig. 3A). The mean of the distance of

2 the highest correlation, $D m$, was 2.61. $D m$ did not present a clear response to variation in $Q$

3 (Fig. 3C). The greatest distance with a significant correlation, $D s$, showed the same tendency

4 as the maximal correlation, $R m$, increasing with $Q$ to a maximum at $Q=0.75$ (Fig. 3D).

The value of $Q=0.75$ was chosen to perform the second set of simulations. This $Q$

6 gave an intermediate value of the proportion of high quality habitat $\left(P_{H}=0.5\right)$ and the highest

7 contrast in growth rates between high and low quality habitat $(\delta=0.06$, Table 2$)$.

\subsection{Effects of aggregation of the habitat and dispersal on the correlation}

10

\section{patterns}

For each of the four buffer radii, the correlation between the local population

abundance in each cell and the proportion of surrounding H-habitat increased with the spatial aggregation of the habitat across the landscape (Fig. 4). The correlation patterns also depended on the dispersal model (Fig. 5), particularly for the two first buffer radii (D1 and $D 2)$, for which the correlation was higher for the Step than for the $12 \mathrm{nn}$ dispersal model and also higher for the $12 \mathrm{nn}$ than for the $2 \mathrm{Dt}$ dispersal model. The correlation value was not influenced by the dispersal rate (mean correlation for $m=0.05: 0.47 \pm \mathrm{sd} 0.34 ; m=0.075: 0.49$ $\pm \operatorname{sd} 0.35 ; m=0.1: 0.50 \pm \mathrm{sd} 0.37)$

$R m$ increased with increasing spatial aggregation of the habitat and decreased with increasing dispersal distance, irrespective of the level of aggregation of the habitat (Fig. 6A). $D m$ increased both with increasing dispersal distances and level of aggregation of the habitat (Fig. 6B). Ds was higher in landscapes with spatial aggregation than in random landscapes, but did not vary with the dispersal distance (Fig. 6C). 


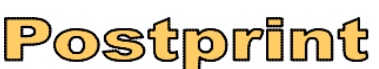

Version définitive du manuscrit publiée dans / Final version of the manuscript published in :

Ecological Complexity (2013), Vol. 15, p. 62-70, DOI: 10.1016/j.ecocom.2013.02.008

Journal homepage: www.elsevier.com/locate/ecocom

\section{4. Discussion}

In the present study, we show that both species population parameters and landscape characteristics simultaneously affect patterns of landscape correlation. The value and distance of maximal correlation were sensitive to variation in habitat quality, dispersal distances and the level of aggregation of the habitat; the greatest distance of significant correlation was affected by landscape variation in habitat quality.

\subsection{Effects of the variation in habitat quality on the correlation patterns}

As expected, the correlations between local population abundance in sampling cells and the surrounding amount of favourable habitat were positive in the case of non-random dispersal (Fig. 3). The correlation increased with increasing variation in the habitat quality of the whole landscape, up to a maximal value that corresponded to equal proportions of $\mathrm{H}$ - and L-habitat (i.e. maximal habitat heterogeneity) and maximal difference in quality between $\mathrm{H}$ and L-habitat types. These results provide support for our interpretation that higher correlations are a consequence of highly contrasted habitat qualities and/or high global proportion of high quality habitat over the landscape. This might result from the proportion of high quality habitats, within buffers, following a binomial distribution, with maximum variance at $P_{H}=0.5$. This cannot be the only explanation, however, as correlations were higher at $P_{H}=0.25$ than at $P_{H}=0.75$ (both for $\delta=0.04$ and $\delta=0.06$ ), which would not be expected for the binomial distribution. A practical issue for Landscape Ecologists is, therefore, that ranking habitat quality for species based on values of correlation will produce misleading or anomalous results if the proportions of habitat are not constant over the landscape (Tischendorf, 2001; Rusch et al., 2011).

We found that, the scale of effect measured as $D m$ neither depended on proportion of good quality habitat nor on differences of quality, $\delta$, between $\mathrm{H}$ - and L-habitats; $\mathrm{H}-$ and L- 


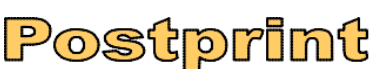

Version définitive du manuscrit publiée dans / Final version of the manuscript published in :

Ecological Complexity (2013), Vol. 15, p. 62-70, DOI: 10.1016/j.ecocom.2013.02.008

Journal homepage: www.elsevier.com/locate/ecocom

1 habitat quality differences largely determined the local population size and global abundance

2 over the landscape. This finding contrasts with the conclusion of Jackson and Fahrig (2012)

3 that "population size (and the underlying population growth rate that leads to population size)

4 may be a strong negative predictor of scale of effect". As with Jackson and Fahrig (2012), the

5 exact mechanism for our result is difficult to pinpoint. However, the discrepancy between the

6 results may be due to differences in the modelling approaches used for dispersal. In our first

7 set of simulations, dispersal distances were short implying that, at each time step, it was only

8 the population abundance within the close neighbourhood that affected abundance of focal

9 patch. In Jackson and Fahrig (2012), individuals could move longer distances, and the

10 abundance of the whole population abundance may impact abundance of focal patch. Such

11 'heavy-tails' to the distribution of dispersal distances can lead to 'super-diffusion' (Clark,

12 1998; Viswanathan et al., 2011) and decrease the correlation pattern between local abundance

13 and surrounding habitat amount.

\subsection{Effects of the aggregation of the habitat and dispersal parameters on the}

\section{correlation patterns}

Our findings for the aggregation of the type of habitat quality and species dispersal were more intuitive. The value of a correlation depended on the dispersal model, with the strength of the correlations decreasing with increasing average dispersal distance (Fig. 5). The effect was consistent with increasing dispersal homogenizing the abundance of populations among cells, through an exchange of individuals (Bowler and Benton, 2009). Dispersal reduces correlation values because all cells will tend to have similar population abundances. Long distance dispersers will also tend not to perceive small scale landscape heterogeneities because heterogeneity among buffers decreases as dispersal distances increase (Baguette and Van Dyck, 2007). Correlation coefficients also increased between random landscapes and 


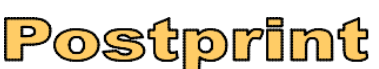

Version définitive du manuscrit publiée dans / Final version of the manuscript published in :

Ecological Complexity (2013), Vol. 15, p. 62-70, DOI: 10.1016/j.ecocom.2013.02.008

Journal homepage: www.elsevier.com/locate/ecocom

1 landscapes with aggregated habitat (Fig. 6), probably in part because the level of aggregation

2 increased the apparent contrast between $\mathrm{H}$ - and L-habitat landscape composition. However,

3 there was no effect of the level of aggregation, despite the highly contrasted maps we used

4 (Fig. A2 in the Supplementary Material). Increasing the aggregation of the habitat within the

5 landscape impacts the connectivity of good quality habitat cells, independent of habitat

6 proportion, and affects the spatial structure of populations over the landscape (Tischendorf,

7 2001).

As explained, we found that landscape correlations depended on the dispersal model

9 (Fig. 5), with the strength of the correlation decreasing with increasing average dispersal

distance; and effect consistent with homogenization. However, where migration is restricted

11 to the near neighbourhoods, strong spatial structuring of population abundances can result.

12 Populations close to high quality habitat would tend to have higher abundances (e.g. Ockinger

13 and Smith, 2007); thus increasing correlation. We did not, though, detect an expected

14 influence of dispersal rate on the pattern of correlation. The value of the correlation was more

15 related to the spatial distribution of displacement events than to the rate (frequency) of

16 displacements. Interestingly, the variation in correlation coefficients achieved with the

17 different dispersal models was consistent across the three levels of aggregation of the habitat 18 across the landscape.

\subsection{Accuracy of the indices describing correlation patterns}

The indices of correlation that might be used by landscape ecologists ( $R m, \mathrm{Dm}$ and

$D s$ ) were found to be related both to population dynamics parameters and global landscape

characteristics. The highest correlation coefficient, $R m$, appeared to summarize all the

24 correlation effects. High values of $R m$ occurred in landscapes with aggregated habitat and/or 


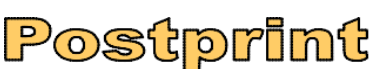

Version définitive du manuscrit publiée dans / Final version of the manuscript published in :

Ecological Complexity (2013), Vol. 15, p. 62-70, DOI: 10.1016/j.ecocom.2013.02.008

Journal homepage: www.elsevier.com/locate/ecocom

1 dispersal. This would suggest that correlations are unlikely to be observed for species with

2 relatively long distance dispersal, with respect to the scales of habitat heterogeneity.

Landscape characteristics and population dispersal also impacted the distances of

4 observed correlations between the local population abundance and the proportion of high

5 quality cells. In empirical studies, the maximal extent of significant correlation (e.g. Carrière

6 et al., 2006), the range of distances that provided significant correlations (e.g. Roschewitz et

7 al., 2005; Thies et al., 2005) and the distance providing the strongest correlation (e.g. Thies et

8 al., 2003) have been used to infer both the spatial scales that species are influenced by

9 landscape characteristics and, more rarely, dispersal ability. Here, we analysed $D m$ and $D s$ as

10 two synthetic variables to evaluate the distance effects of favourable habitat quantity. $\mathrm{Dm}$ was

11 found to be very sensitive to the dispersal model and increased with average dispersal

12 distance, as has been assumed in empirical studies. However, it was also sensitive to the

13 aggregation of the habitat (Fig. 6). As a consequence, we believe it would be difficult to

14 derive the mean dispersal distance of a given species using the measurement of the distance of

15 the highest correlation, $D m$, alone. We also found that $D s$ did not depend on population

16 dynamics parameters or on landscape structure (for landscapes with aggregated habitat), but

17 increased only with the variation in habitat quality. It thus does not appear to be a very useful

18 statistic to infer dispersal. Perhaps most interestingly, all the indices of correlation we

19 considered in this study were found not to be affected by the rate of dispersal. This would

20 suggest to us that estimates of dispersal rate cannot be derived from observed patterns of

21 correlation.

22

\subsection{Modelling context}




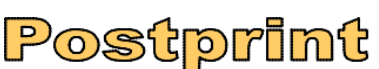

Version définitive du manuscrit publiée dans / Final version of the manuscript published in :

Ecological Complexity (2013), Vol. 15, p. 62-70, DOI: 10.1016/j.ecocom.2013.02.008

Journal homepage: www.elsevier.com/locate/ecocom

1

2

3

4

5

6

7

8

9

10

11

12

14

15

16

18

19

20

In this study, we used representations of simple natural landscapes and population dynamics in order to understand qualitative landscape-correlation relationships. We chose to focus solely only on the representation of the spatial variation of habitat quality and to keep it stable along the simulations, which would likely not be the case in all landscapes (Le Féon et al., 2012). The dynamics of the populations were also greatly simplified and rather than modelling particular taxa, we considered only simple, general processes. This generic approach allowed us to highlight general trends that can be readily interpreted and gave important insight into analysing correlation patterns between local population abundances and landscape features. However, some of the simulation characteristics we used may be more representative of some systems than others. The modelled local population dynamics described the dynamics of an annual species with population growth during a favourable season, bracketed by large death rates in winter that re-set the populations to low levels for the start of the following year. This population dynamic system resembles that of many pest arthropods in temperate agriculture.

\section{Conclusion}

Our results indicate that global landscape structure and composition affect the patterns of correlation between population abundance and amounts of favourable habitat. Such global landscape characteristics therefore need to be considered in analyses that intend to derive population dynamic parameters from empirical, landscape correlation studies. Inferring either the quality of a habitat from the intensity of the correlation or the distance of dispersal from the distance of the highest correlation requires knowledge of whether the habitat is aggregated or not. Our work confirms that it is necessary to control for the interaction between landscape structure and population dynamics parameters, such as dispersal distance, possibly by using landscape replication, and to report details about the proportion and spatial distribution of the 


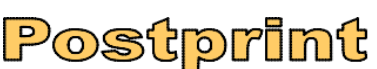

Version définitive du manuscrit publiée dans / Final version of the manuscript published in :

Ecological Complexity (2013), Vol. 15, p. 62-70, DOI: 10.1016/j.ecocom.2013.02.008

Journal homepage: www.elsevier.com/locate/ecocom

\section{References}

2 Aldridge, C.L., Boyce, M.S., 2007. Linking occurrence and fitness to persistence: Habitatbased approach for endangered Greater Sage-Grouse. Ecol. Appl. 17, 508-526.

Baguette, M., Van Dyck, H., 2007. Landscape connectivity and animal behavior: functional grain as a key determinant for dispersal. Landscape Ecol. 22, 1117-1129.

Bender, D.J., Tischendorf, L., Fahrig, L., 2003. Using patch isolation metrics to predict animal movement in binary landscapes. Landscape Ecol. 18, 17-39.

Bianchi, F.J.J.A., Booij, C.J.H., Tscharntke, T., 2006. Sustainable pest regulation in agricultural landscapes: a review on landscape composition, biodiversity and natural pest patch distance. Oikos 118, 403-412.

Brennan, J.M., Bender, D.J., Contreras, T.A., Fahrig, L., 2002. Focal patch landscape studies for wildlife management: optimizing sampling effort across scales. In: Liu J, Taylor WW (eds) Integrating landscape ecology into natural resource management. Cambridge

Campagne, P., Buisson, E., Varouchas, G., Roche, P., Baumel, A., Tatoni, T., 2009. Modeling

Carrière, Y., Ellsworth, P.C., Dutilleul, P., Ellers-Kirk, C., Barkley, V., Antilla, L., 2006. A GIS-based approach for areawide pest management: the scales of Lygus hesperus movements to cotton alfalfa, weeds, and cotton. Entomol. Exp. Appl. 118, 203-210. paleorecord. Am. Nat. 152, 204-224. 


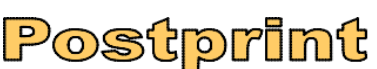

Version définitive du manuscrit publiée dans / Final version of the manuscript published in :

Ecological Complexity (2013), Vol. 15, p. 62-70, DOI: 10.1016/j.ecocom.2013.02.008

Journal homepage: www.elsevier.com/locate/ecocom

1 Decante, D., Van Helden, M., 2006. Population ecology of Empoasca vitis (Gothe. and

2 Scaphoideus titanus, Ball) in Bordeaux vineyards: Influence of migration and landscape.

3 Crop Prot. 25, 696-704.

4 Jackson, H.B., Fahrig, L., 2012. What size is a biologically relevant landscape? Landscape

Ecol. 27, 939-941.

6 Jeanneret, P., Schupbach, B., Pfiffner, L., Walter, T., 2003. Arthropod reaction to landscape and habitat features in agricultural landscapes. Landscape Ecol. 18, 253-263.

Jepsen, J.U., Baveco, J.M., Topping, C.J., Verboom, J., Vos, C.C., 2005. Evaluating the effect of corridors and landscape heterogeneity on dispersal probability: a comparison of three spatially explicit modelling approaches. Ecol. Model. 181, 445-459.

Le Féon, V., Burel, F., Chifflet, R., Henry, M., Ricroch, A., Vaissière, B.E., Baudry, J., 2012. Solitary bee abundance and species richness in dynamic agricultural landscapes. Agric. Ecosyst. Environ. In press, doi:10.1016/j.agee.2011.06.020.

Moilanen, A., Hanski, I., 1998. Metapopulation dynamics: Effects of habitat quality and

Moilanen, A., Nieminen, M., 2002. Simple connectivity measures in spatial ecology. Ecology $83,1131-1145$.

Moser, D., Drapela, T., Zaller, J.G., Frank, T., 2009. Interacting effects of wind direction and resource distribution on insect pest densities. Basic Appl. Ecol. 10, 208-215.

Ockinger, E., Smith, H.G., 2007. Semi-natural grasslands as population sources for pollinating insects in agricultural landscapes. J. Appl. Ecol. 44, 50-59.

Pulliam, H, 1988. Sources, sinks, and metapopulation regulation. Am. Nat. 132, 652-661. 
Version définitive du manuscrit publiée dans / Final version of the manuscript published in :

Ecological Complexity (2013), Vol. 15, p. 62-70, DOI: 10.1016/j.ecocom.2013.02.008

Journal homepage: www.elsevier.com/locate/ecocom

1 Zaller, J.G., Moser, D., Drapela, T., Schmoger, C., Frank, T., 2008. Effect of within-field and

2 landscape factors on insect damage in winter oilseed rape. Agric. Ecosyst. Environ. 123, $3 \quad 233-238$.

4 Zurell, D., Berger, U., Cabral, J., Jeltsch, F., Meynard, C., Muenkemueller, T., Nehrbass, N.,

5 Pagel, J., Reineking, B., Schroeder, B., Grimm, V., 2010. The virtual ecologist approach:

6 simulating data and observers. Oikos 119, 622-635.

7 
Version définitive du manuscrit publiée dans / Final version of the manuscript published in :

Ecological Complexity (2013), Vol. 15, p. 62-70, DOI: 10.1016/j.ecocom.2013.02.008

Journal homepage: www.elsevier.com/locate/ecocom

\section{TABLES}

2 Table 1. Variable names and description.

\begin{tabular}{lll}
\hline \multicolumn{1}{c}{ Category } & Parameter name & \multicolumn{1}{c}{ Description } \\
\hline Population growth & $r_{H}$ & Growth rate in high quality habitat \\
& $r_{L}$ & Growth rate in low quality habitat \\
& $\delta=r_{H}-r_{L}$ & Growth rate difference between habitats \\
Dispersal & $m$ & Dispersal rate \\
& $d i s p$ & Dispersal model (qualitative) \\
Landscape & $P_{H}$ & Proportion of high quality habitat \\
& $S$ & Aggregation of habitat quality across the \\
& $Q$ & landscape (qualitative) \\
Correlation description & $R m$ & Variation in habitat quality \\
& $D m$ & Maximal correlation \\
& $D s$ & Distance of maximal correlation \\
& & Greatest distance with a significant correlation \\
\hline
\end{tabular}

3 


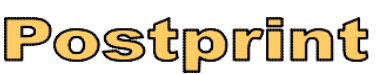

Version définitive du manuscrit publiée dans / Final version of the manuscript published in :

Ecological Complexity (2013), Vol. 15, p. 62-70, DOI: 10.1016/j.ecocom.2013.02.008

Journal homepage: www.elsevier.com/locate/ecocom

1 Table 3. Mean correlation between population abundance and surrounding proportion of high

2 quality habitat, and percentage of significant positive or negative correlations.

\begin{tabular}{lccc}
\hline $\begin{array}{c}\text { Disperal } \\
\text { model }\end{array}$ & Mean correlation & $\begin{array}{c}\text { Percentage of significant } \\
\text { and positive correlations }\end{array}$ & $\begin{array}{c}\text { Percentage of significant } \\
\text { and negative correlations }\end{array}$ \\
\hline Step & $0.73( \pm$ SE 0.011) & 92.2 & 0 \\
$12 n n$ & $0.66( \pm$ SE 0.011) & 86.7 & 0 \\
$2 D t$ & $0.56( \pm$ SE 0.012$)$ & 76.9 & 0 \\
Random & $0.01( \pm$ SE 0.011$)$ & 2.2 & 4.2 \\
\hline
\end{tabular}

3

4 
Version définitive du manuscrit publiée dans / Final version of the manuscript published in :

Ecological Complexity (2013), Vol. 15, p. 62-70, DOI: 10.1016/j.ecocom.2013.02.008

Journal homepage: www.elsevier.com/locate/ecocom

\section{FIGURES CAPTION}

2

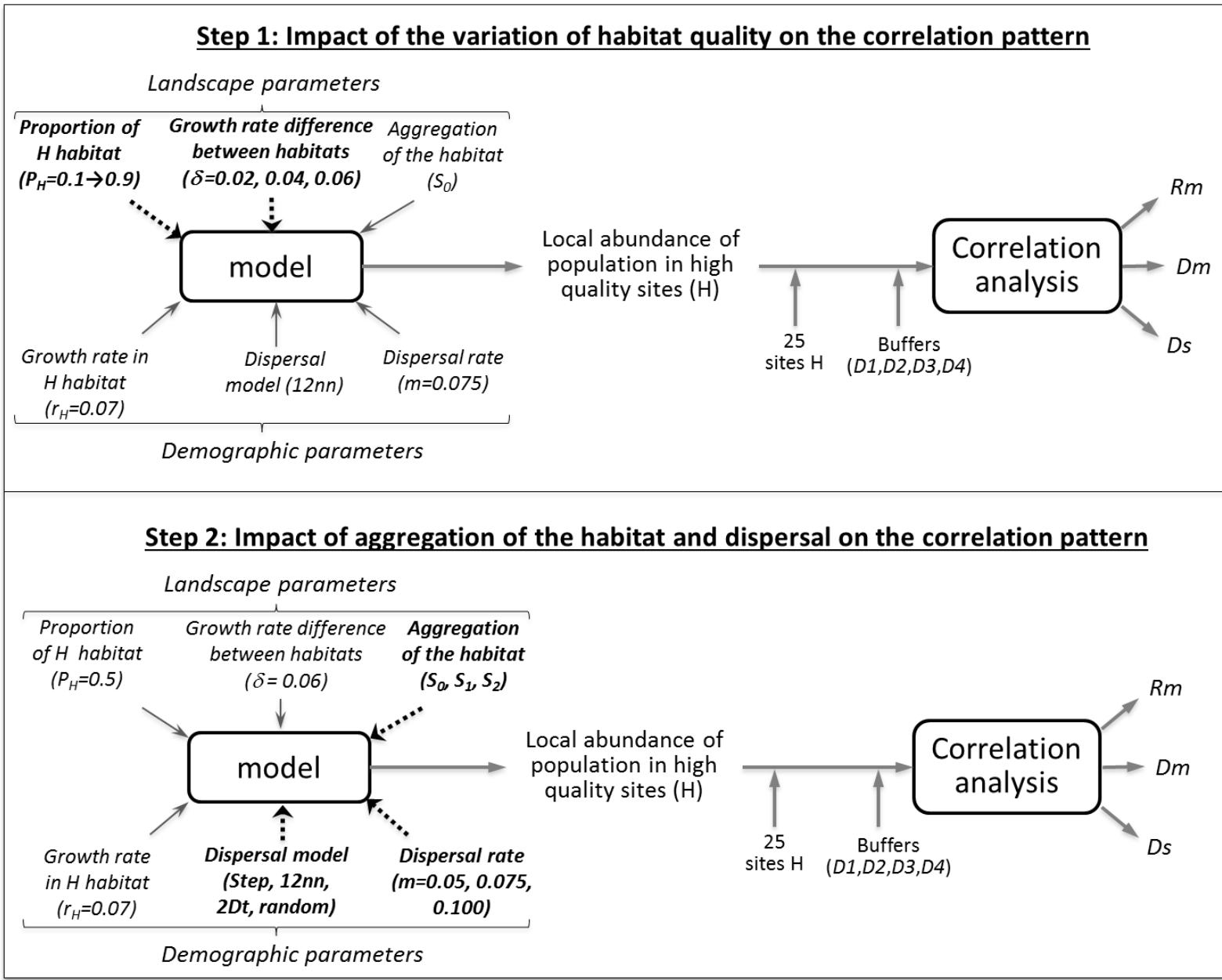

4 Fig. 1. Simulation designs for each one of the two studied questions. On the left part of the

5 scheme describing the landscape and population demographic parameters used in the

6 simulating model (Table 1), variable parameters are indicated in bold with dashed arrows and

7 fixed parameters are indicated with small full-line arrows. On the right part of the scheme

8 describing the correlation analysis, three output parameters were computed to describe

9 intensity $(\mathrm{Rm})$ and spatial extent of the correlations ( $\mathrm{Dm}$ and $\mathrm{Ds}$ ) according to simulations. 


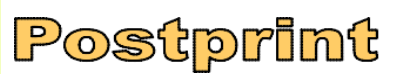

Version définitive du manuscrit publiée dans / Final version of the manuscript published in :

Ecological Complexity (2013), Vol. 15, p. 62-70, DOI: 10.1016/j.ecocom.2013.02.008

Journal homepage: www.elsevier.com/locate/ecocom

(A) $S_{0} ; P_{H}=0.1$

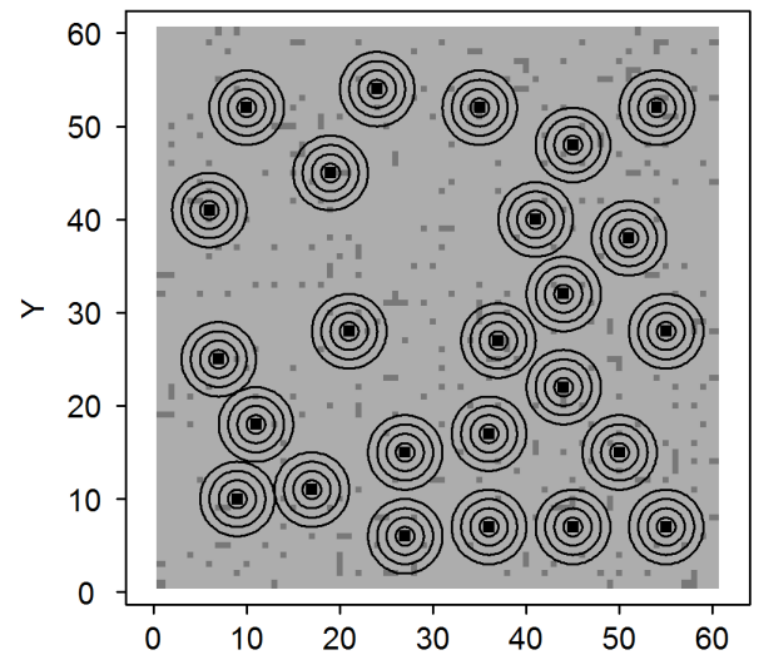

(C) $S_{1} ; P_{H}=0.5$

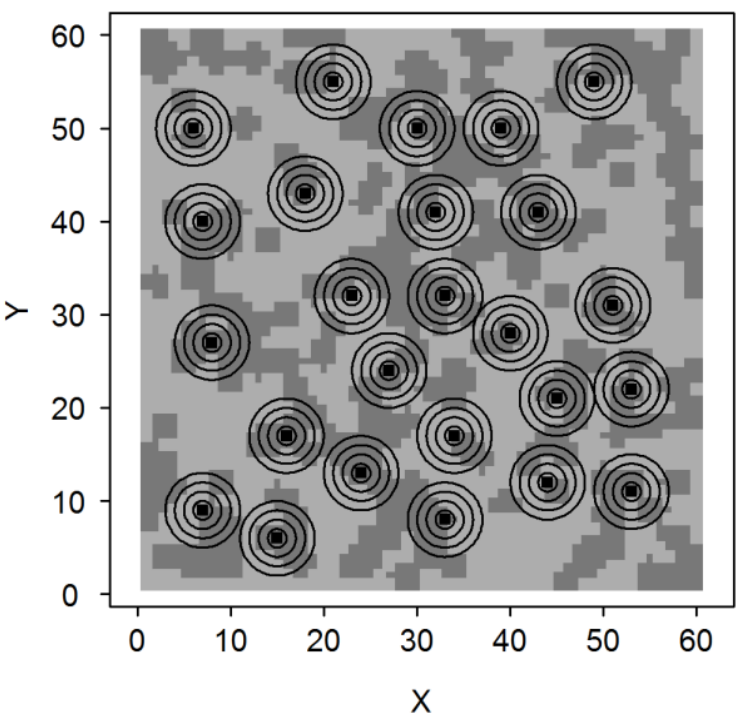

(B) $S_{0} ; P_{H}=0.5$

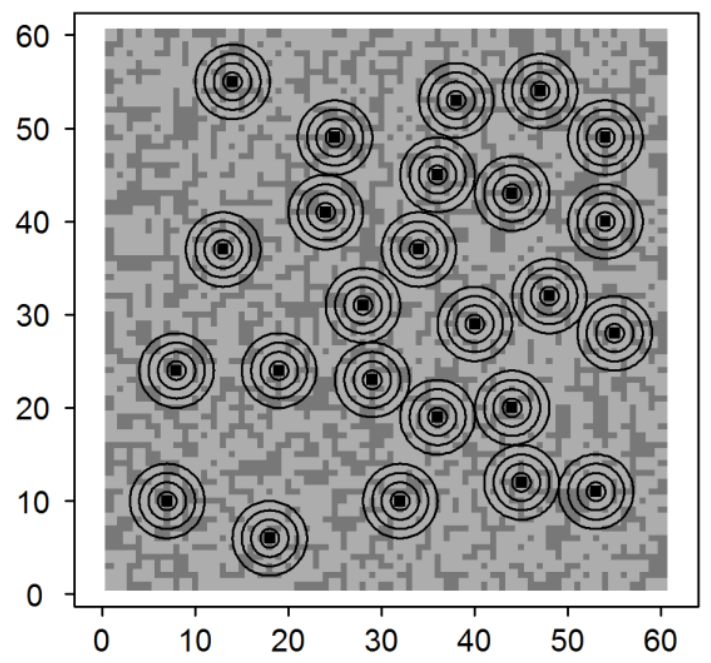

(D) $S_{2} ; P_{H}=0.5$

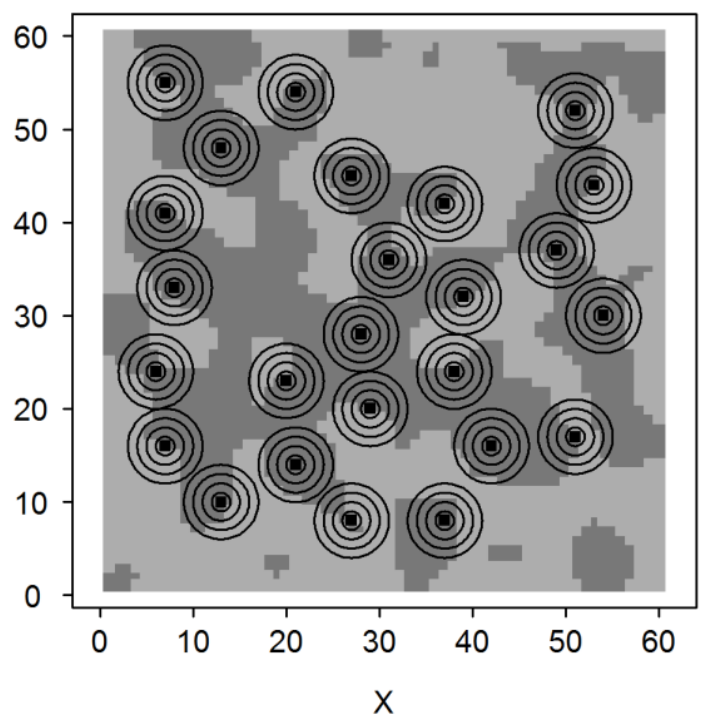

2 Fig. 2. Maps of some landscape configuration used for the simulations, including position of

3 the selected cells and the four buffer zones $(D 1, D 2, D 3, D 4)$ used for the calculation of

4 correlations: random landscape with a proportion of H-habitat $P_{H}=0.1$ (A) and 0.5 (B),

5 landscapes with low (C) and high (D) level of aggregation of the habitat. Cells corresponding

6 to L-habitat are represented by light grey dots; cells corresponding to H-habitat by dark grey

7 dots. The 25 selected H-cells used for the correlation between population abundance and the

8 proportion of surrounding $\mathrm{H}$-habitat are indicated by black dots and are surrounded by the

9 four buffer zones of increasing radius distances. 
Version définitive du manuscrit publiée dans / Final version of the manuscript published in :

Ecological Complexity (2013), Vol. 15, p. 62-70, DOI: 10.1016/j.ecocom.2013.02.008

Journal homepage: www.elsevier.com/locate/ecocom

(A)

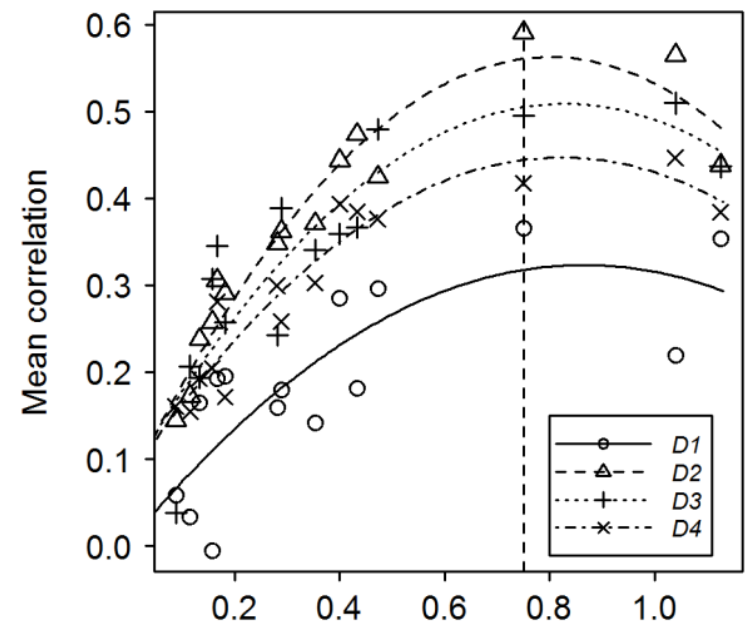

(C)

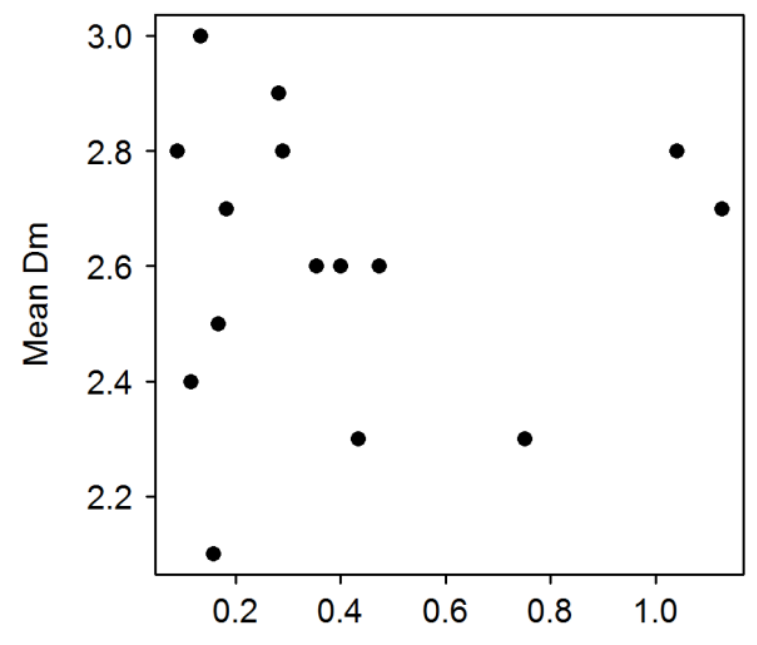

$Q$
(B)

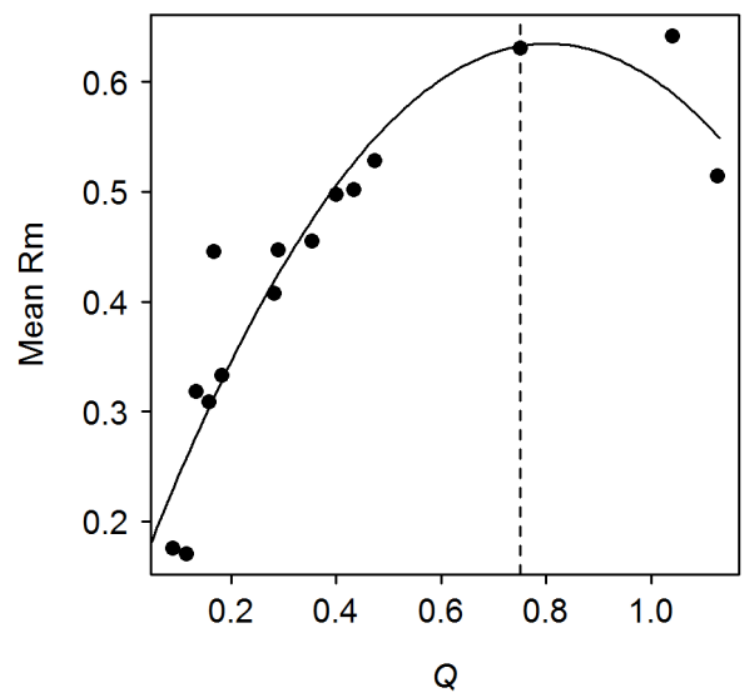

(D)

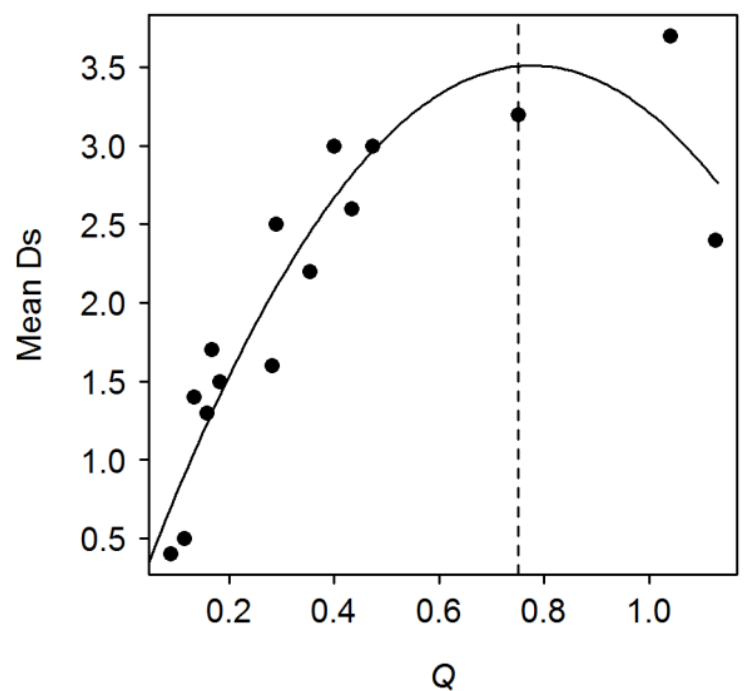

2 Fig. 3. Effect of the variation of habitat quality $Q$ on (A) the correlation between local

3 population abundance and surrounding proportion of $\mathrm{H}$-habitat, (B) the highest correlation,

4 (C) the distance of the highest correlation and (D) the greatest distance at which a significant

5 correlation occurred. Each point is a mean value over the ten replicates of a given value of $Q$.

6 Curves are second-order polynomial regressions: (A)-D1: $\mathrm{R}^{2}=0.64$; (A)-D2: $\mathrm{R}^{2}=0.94$; (A)-D3:

$7 \quad \mathrm{R}^{2}=0.77,(\mathrm{~A})-D 4: \mathrm{R}^{2}=0.91 ;(\mathrm{B}): \mathrm{R}^{2}=0.87 ;(\mathrm{D}): \mathrm{R}^{2}=0.87$. 


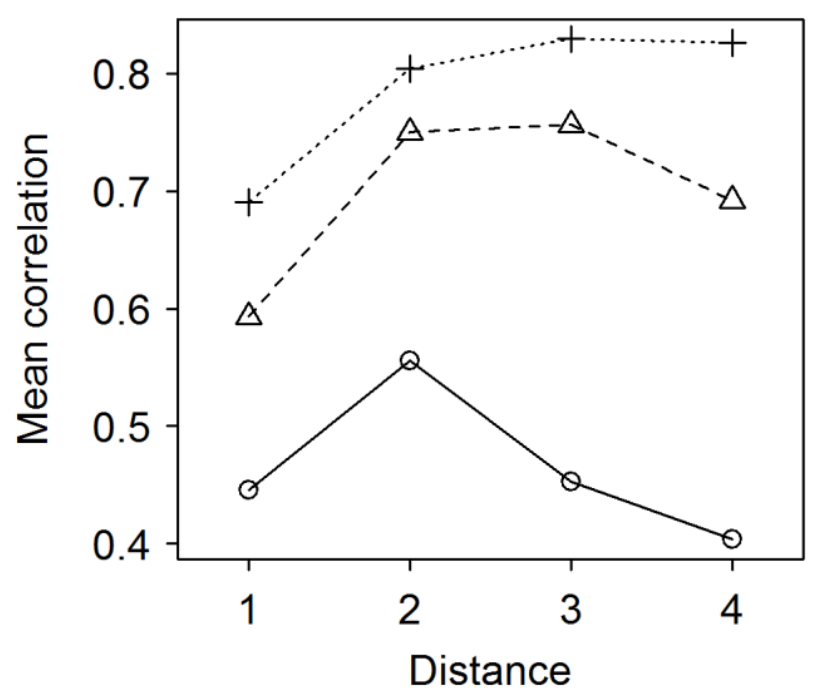

1

2 Fig. 4. Effect of the aggregation of the habitat $\left(\circ S_{0}, \triangle S_{1},+S_{2}\right)$ on the value of the

3 correlation between local population abundance and surrounding proportion of $\mathrm{H}$-habitat in

4 buffer zones of increasing radius distances $(D 1, D 2, D 3$ and $D 4)$. Each point is a mean over

5 ten replicates of a given level of aggregation $\left(S_{0}, S_{1}, S_{2}\right)$ and the combination of dispersal

6 parameters, except the Random dispersal model (three dispersal rates $m$ and three dispersal

7 models Step, 12nn, 2Dt).

8 


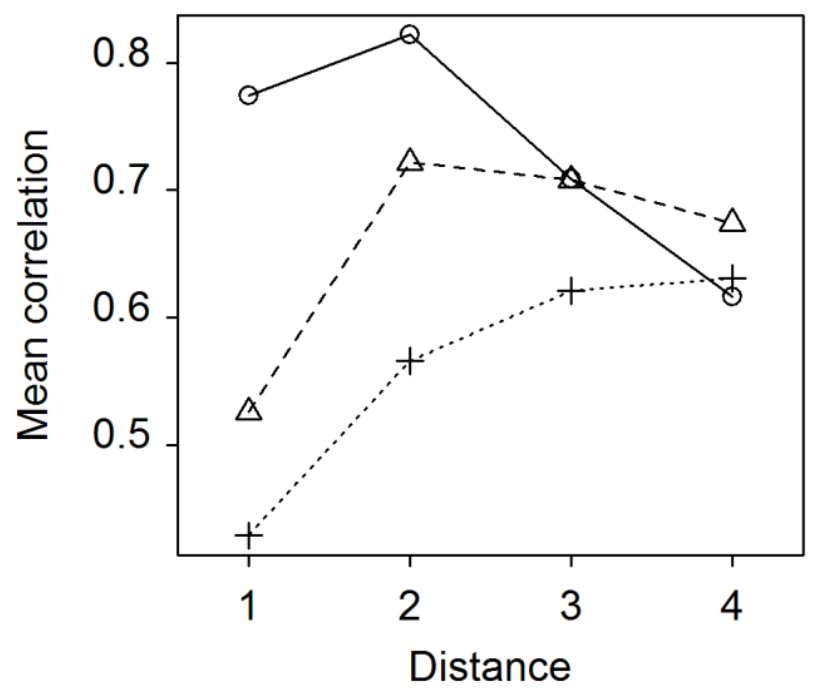

1

2 Fig. 5. Effect of the dispersal model ( $O$ Step, $\triangle 12 n n,+2 D t)$ on the value of the correlation

3 between local population abundance and surrounding proportion of $\mathrm{H}$-habitat in buffer zones

4 of increasing radius distances $(D 1, D 2, D 3$ and $D 4)$. Each point is a mean over the

5 combinations of other parameters (three dispersal rates $(m=0.05,0.075,0.100)$, three levels

6 aggregation of the habitat $\left(S_{0}, S_{1}, S_{2}\right)$ and ten replicates of a given landscape structure). 
Version définitive du manuscrit publiée dans / Final version of the manuscript published in :

Ecological Complexity (2013), Vol. 15, p. 62-70, DOI: 10.1016/j.ecocom.2013.02.008

Journal homepage: www.elsevier.com/locate/ecocom
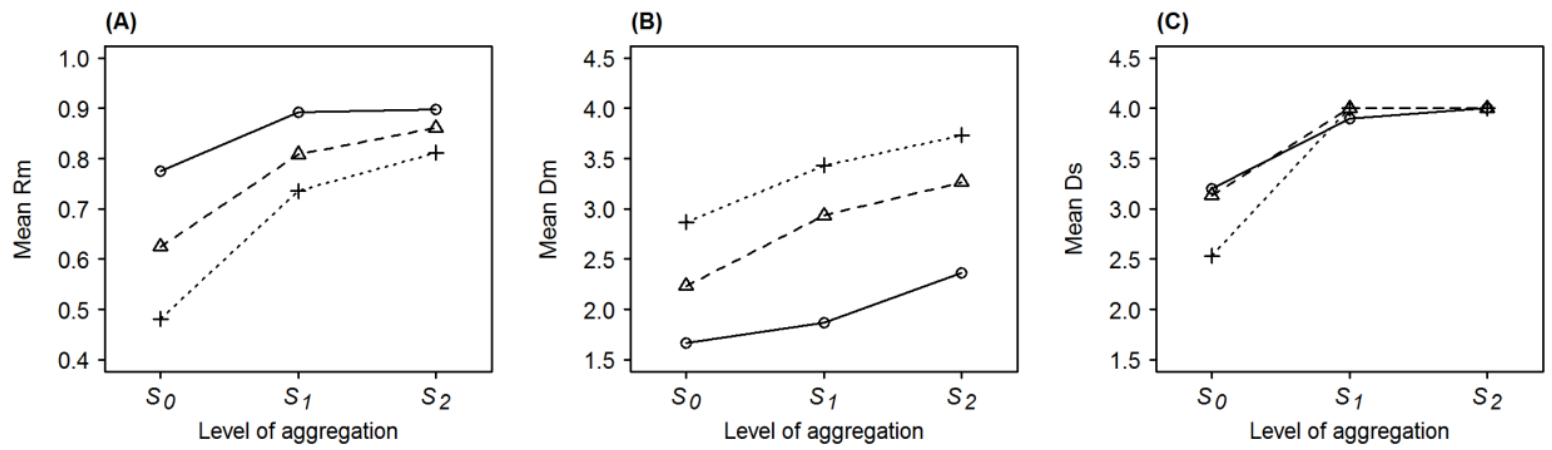

2 Fig. 6. Effect of aggregation of the habitat $\left(S_{0}, S_{1}, S_{2}\right)$ and the dispersal model (O Step, $\triangle$

$312 n n,+2 D t)$ on (A) the highest correlation, $R m$; (B) the distance of the highest correlation,

$4 \mathrm{Dm}$; and (C) the greatest distance at which a significant correlation occurred, Ds. Each point

5 is a mean value over the three dispersal rates and the ten replicates of a given level of

6 aggregation $\left(S_{0}, S_{1}, S_{2}\right)$.

7 